\title{
Benefiting From Authentic Education To A Sustainable Social Development
}

Chandana Watagodakumbura, RMIT University, Melbourne, Australia

\begin{abstract}
Authentic education provides a unique learning experience to individual learners, specifically by addressing their psychological and neurological needs. The assessment of learners is done through generic attributes that have more validity and relates to intrinsic learner characteristics that could last throughout the life span of the learner. Authentic education looks at the general term education more broadly and deeply, and from multiple perspectives. As the individual learners are identified uniquely through authentic education, it embraces diversity within the human species more broadly and meaningfully. Learners are encouraged to pursue higher-order learning sending them through a complete learning cycle; this engages learners deeply to the task and provides a lasting experience, enabling individuals to reach their full potential. Authentic education aims at providing personal development for individuals broadly, not merely a career development, while still paving a better way to map individual preferences to more suitable career paths. Through authentic education, we get to value human resources much more than related economic aspects, making a significant difference to our current approaches and focus; it has the promise to effect a significant positive social change towards a sustainable development. The purpose of this study is to discuss conceptualising authentic education, multiple perspectives, better educational outcomes, learners embracing diversity, higher order learning, individual characteristics to related career paths, holistic personal development, social change valuing human resources, and consistent and predictable social development.
\end{abstract}

Keywords: Authentic Education; Education Outcomes; Embracing Diversity; Higher Order Learning; Personal Development; Valuing Human Resources; Social Development

\section{INTRODUCTION}

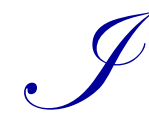

$\mathrm{n}$ this paper, the author first presents his conceptual view of authentic education briefly. In the subsequent sections the benefits of such an authentic education system to individuals as well as to the society at large are highlighted from a number of different perspectives. Such a system essentially allows individuals to develop to their authentic and unique full potential levels, making them more satisfied and contended. As a result, the societies will benefit from such individuals, who are not only diverse in characteristics but have reached to higher levels in personnel developments. On the whole, an authentic education system has the undeniable promise of making a significant positive social change focusing sustainable development.

\section{CONCEPTUALISING AUTHENTIC EDUCATION}

Within an authentic education framework (Watagodakumbura), as the author conceptualises, learners' individual psychological and neurological characteristics are given consideration and accepted as they are, promoting inclusive practices. For example, emotional and other high sensitivities commonly found in gifted and creative personnel are not considered as constraints, rather they enrich a neurodiverse (Armstrong) society to operate in a more balanced manner. In an authentic education framework, learning preferences of auditory sequential learners as well as visual spatial learners (Silverman, 2002; 1998) are given consideration equally and unbiasedly and these preferences are mapped into to related career paths so that individuals of both categories enjoy their work more naturally, or intrinsically. Learners with high developmental potential, meaning the inclination towards a highly empathetic, satisfied and productive human being, get conducive environments to reach higher levels of 
development, similar to a self-actualised (Maslow, 1968; 1993) state. An authentic education system sends learners through a lasting deep learning (Biggs and Tang; Entwistle) and critical thinking (Paul and Elder) experience, for which human brains are capable of under conducive teaching-learning environments; human brains are treated as parallel processors that are capable of dealing with multiple inputs and solving complex problems unlike machines, or computers that are good at executing routine steps in reaching specific answers very high speeds (Beale and Jackson). Following the fundamentals of neuroscience, many physical parts of the brains are incorporated into learning with methodologies similar to Kolb's experiential learning cycle (Kolb; Zull) and constructivist theory of learning (Biggs and Tang); learning has physical meaning in which neurons in the brain grow (Diamond, 1996; 2001) to develop dense communication network indicating deep learning, as opposed to surface, or superficial learning, has taken place. In an authentic educational practice, learner evaluation is done using generic learning attributes that are associated with learners' intrinsic characteristics, instead of an indication of how well a learner has prepared in a specific area of study prior to an assessment; these generic learning attributes carry qualitative values that are valid throughout one's life span as they relate to one's psychological and neurological characteristics very well.

\section{GIVES THE GENERAL TERM OF EDUCATION A DEEPER AND BROADER MEANING VIEWING FROM MULTIPLE PERSPECTIVES, RESULTING BETTER EDUCATIONAL OUTCOMES}

Within an authentic education system, we have understood the general term of education more deeply and broadly viewing from multiple points of view; it goes beyond the superficial levels of understanding it and promises significant benefits in terms of educational outcomes. When looking at the term education in a contemporary society, we need to have a multidisciplinary perspective; the discipline of pedagogy alone will not define it adequately. We essentially need to integrate perspectives from a number of other disciplines such as humanistic and gifted psychology, neuroscience and neurology to better define the term education. It will result in a more inclusive and sustainable meaning, covering wider member communities of our society. Even though very useful facts and findings have emerged from different disciplines in contributing defining the term education, we do not get to see the real picture when they are disintegrated from each other. When looking from an integrated perspective, we are able to understand the possible benefits that are promised. These promises would start from providing just a better environment for learners to effecting a considerable positive social change, as highlighted in the following paragraphs.

\section{ALLOWS UNIQUE IDENTIFICATION OF LEARNERS EMBRACING DIVERSITY}

An authentic education system will identify individual learners uniquely through their psychological and neurological characteristics. For example, learners will be identified whether they are more inclined for auditory sequential learning or visual spatial learning. Further, the learners will be identified whether they demonstrate any overexcitabilities (Dabrowski, 1970; 1972; 1977) such as emotional, imaginational or intellectual. These characteristics are intrinsic to each individual and would span a lifetime. As a society, our awareness on individual differences, or diversity, will grow accepting each other much more than now. This increased awareness will apply specifically to understanding the important concept of neurodiversity (Armstrong). We may not define a strict and narrow normal behaviour and label everything outside the band as abnormal; rather we would accept that a wide range of differences that are normal do exit and those wide differences, in fact, enriches our society, similar to different plants that enrich a rainforest. We will be in with a better chance of minimising any misdiagnoses of healthy individuals (Webb, 2005), a concern raised by some prominent healthcare and medical professionals. Raised awareness and acceptance will allow us to minimise having individuals to rely on medication for some psychological differences. For example, we may have to carefully differentiate whether an individual has attention deficit hyperactivity disorder (ADHD) or is it merely psychomotor overexcitability. When the mainstream education system identifies learners' unique psychological and neurological characteristics, it enables us to be inclusive in our practices, getting the due attention to every individual. When every individual get to know about his or her intrinsic nature, he or she would be in a better position to take better decisions, to develop more tolerant, empathetic and contended personalities. Since we are giving significance to human characteristics, or characteristics pertaining to human nature, we disregard, or go beyond, other cultural or extrinsic bias that constraints positive learning environments. 


\section{ALLOWS LEARNERS TO PURSUE HIGHER ORDER LEARNING UNDERGOING A COMPLETE LEARNING CYCLE THAT ENHANCES THE CHANCES OF REACHING THEIR FULL POTENTIAL}

An authentic education system encourages individuals to pursue higher order learning enabling them to reach their full potential. When the assessments target higher end of the Bloom's taxonomy (Biggs; Ramsden), instead of the middle or lower levels, we encourage learners to strive for achieving higher, something they could achieve as human beings, or human nature. Creativity is natural to human species and when we encourage learners to pursue higher order learning, we sharpen their creative instincts, encouraging them to produce creative outputs; unlike robots, or machines, that produce uncreative and routine answers rapidly, we want learners to be creative, producing unique outputs. Different individuals will pursue this path to higher achievement at different paces and reach higher levels at different times, but there will be no ceilings at lower levels stopping them progressing to higher levels. Individuals will not be competing with each other to reach higher levels, rather, will be striving to self-identify one's natural pace to traverse because that is the best pace for oneself. More the productive time a learner can put in pursuing higher order learning, the higher the level of understanding he or she can achieve, or the level of learning achieved is proportional to the amount of productive time spent; there is probably no a two state switch to decide whether one can or cannot. Learners will be going through complete learning cycles as described in Kolb's experiential learning, without being restricted to only some stages. Such practices move learners on a ladder to their full potential, or the state of self-actualisation, as Abraham Maslow (1968; 1993) termed. These selfactualising personnel reaching their full potential are identified to be more creative. There is evidence from neuroscience that neural networks can grow denser making new connections throughout one's lifespan, and as we keep on striving on higher order learning, we can reach higher levels of our potential.

Furthermore, when higher order learning is the focus, it accommodates the visual spatial, or gifted, learners in the mainstream education system rather than leaving them behind or requiring them special education programs. Put differently, when we identify in pedagogy that higher order learning is the way to go, it applies equally well to both visual spatial learners as well as auditory sequential learners. Every individual will be using the generalised knowledge they gained through education in a wide range of situation in life, not only in their careers. As individuals, they will be making better, or more educated, decisions, in everyday situations, not merely in a narrow area related to the specific career. This is one of the prime intensions of an authentic education system; that is preparing learners to succeed as a whole, as better human beings, as better judges of overall social situations, not just in a narrow career area.

\section{PROVIDES OPPORTUNITIES TO MAP INTRINSIC INDIVIDUAL CHARACTERISTICS TO RELATED CAREER PATHS}

When the mainstream education system identifies a learner's intrinsic individual characteristics, mainly the psychological and neurological ones, it helps individuals and organisations to map them to more suitable career paths. In other words, an individual's intrinsic characteristics can be mapped mainly to visual spatial or auditory sequential type work category, as highlighted before. Each work category is given the same level of recognition, or one is not more important than the other, as we essentially need both categories for sustainable social development. When such mappings take place, individuals will find them more at ease and satisfied in their work environments, resulting increased productivity at work place. That is, not only the individuals, but also the organisations will benefit. When the mainstream education system identifies intrinsic learner characteristics over a long period, the organisations do not have to rely on rapidly conducted tests, such as psychometric ones, possibly with much less reliability, to categorise individual candidates. Further, when intrinsic individual characteristics are identified at an early age of the individual, more stressful and demanding, late, significant career changes can be avoided, yielding better career guidance at a relatively early stage. On the whole, we will be able to produce better, or more consistent, career selections for individuals and better career mappings for organisations in our society through an authentic education framework.

\section{ENCOURAGES HOLISTIC PERSONAL DEVELOPMENT, NOT MERELY CAREER DEVELOPMENT}

An authentic education framework signifies the concept of lifelong learning; that is we need to improve as persons, or human beings, throughout our life spans. By improving as a person, or human being, we become more 
satisfied, empathetic and creative individuals. Findings from neuroscience provide evidence that human beings have the capacity to learn throughout their life spans (Diamond, 1996; 2001), contrary to the believes held otherwise, superficially. Education does not end when we start our working careers, and afterwards it is not merely career development we strive at. Within an authentic education framework, we have the opportunity to map our prominent, intrinsic personality characteristics to a career path, but some other weaker characteristics of ours could still be useful in our normal life situations; in continuous personal development we need to improve on those areas that will be useful in ours operation within the society, presently or in future. Ideally, the organisations should provide provisions for their employees to engage in such personal development activities, outside their normal career activities; this could be part of lifelong learning. When we undertake such personal development activities, we will not be simply focusing on a narrow career direction; rather we will be broadening our understanding and knowledge that would be useful in our personal lives. Such personal development activities prepare us better, or insure us better, for unexpected or emergency social situations such as loss of employment; through our broader personal development, or broader knowledge, we will be in a better position to find other suitable employment, even if it is not directly related to the previous one. This positive transition may not be possible if we constrained ourselves to a narrow career paths lacking holistic personal development. An authentic education framework essentially raises the awareness and promotes lifelong learning that enables individuals to prosper continually as persons, or human beings.

\section{ALLOWS LEARNERS TO PENETRATE THROUGH DIVERSE SOCIO-ECONOMIC CONDITIONS}

One of the primary aims of authentic education is to characterise learners based on their psychological and neurological characteristics; that is, this characterisation is based on intrinsic human nature, or human characteristics, rather than something extrinsic. Thus, this characterisation is less reliant on socio-economic conditions that exist in the learners' environment. Authentic education attempts to meet the needs of learners on individual basis, not on group basis; that is, we try to avoid forcing individuals to learn based on what is better for the larger group they belong, which is likely to depend on the socio-economic conditions. Simply accepting differences among individuals as a society itself encourages individuals to pursue unique learning and development paths, based on one's intrinsic characteristics. As a result, the authentic education has the inherent ability to penetrate through socio-economic conditions of the individuals, communities or the larger society. It has the promise of producing learners who are less susceptible to prevailing socio-economic conditions and possible enculturation situations; that is, it enables producing global citizens who can penetrate through the existing local conditions. Further, the learners coming out from an authentic education system are likely to adjust better for different socioeconomic conditions, or in other words, they may find it easier to find a suitable mapping in terms of employments even in a different socio-economic environment. In contemporary education, how we address the issues related the learners from low socio-economic backgrounds are discussed very often. Further, it is possible that some of the learners from low socio-economic backgrounds to be highly gifted, or visual spatial type learners, exposing their usual vulnerabilities to much higher levels; the struggle to make the basic needs of life meet can have a toll on their higher sensitivities, or overexcitabilities. Within an authentic education system, however, the need to explicitly address the issues related to the learners of low socio-economic backgrounds minimises, as such an education binds tightly to the individual person than to external measures; irrespective of the learners' socio-economic background, an authentic education system characterises them as auditory sequential or visual spatial learners and whether they demonstrate any overexcitable neurological characteristics.

\section{ALLOWS A POSITIVE SOCIAL CHANGE VALUING HUMAN RESOURCES AHEAD OF MERE ECONOMIC ASPECTS}

An authentic education framework inherently gives prominence to human resources ahead of any other resource including economic aspects. It identifies individuals uniquely, valuing and accepting their unique characteristics and making them more satisfied and contended, resulting more productive operation within the society. The society as a whole strives to make their members more productive, satisfied and contended, pushing aspects related to economy to a secondary status. This is a more positive change from the existing norm of giving prime importance to economic aspects while pushing the rest including human resources to a level of subprime importance. We make use of economic resources to make human beings reaching higher or full potential rather than making use of, or manipulating, human resources to make better economic status. In an authentic education 
framework, we are directing the significance to the area where it is deserved. While economic aspects, or economic managements, are important, it is only secondary to how effectively and efficiently human resources are utilised. We have more value in fully functioning human beings with much less waste than a large pile of economic gains. There will be synergy within societies to improve its members' productivity rather than tug of war among groups within societies. An authentic education system essentially raises the awareness of the significance of having more satisfied, empathetic, creative and productive human beings ahead of piles of nominal economic gains. Mismanaged human resources could cause years of high economic gains to be vanished in no time.

\section{ALLOWS FOR SUSTAINABLE, MORE CONSISTENT AND PREDICTABLE SOCIAL DEVELOPMENT}

In the field of education, an authentic education framework gives the opportunity for every individual to engage in learning in a unique manner that suits him or her the best. It aims at providing each individual an opportunity to reach his or her full potential. Allowing individuals to reach their full potential results in selfactualising, or psychologically healthy, personnel, as Abraham Maslow referred to: individuals will be engaged in a lifelong personal development, or education, process, resulting positive motivation. The end result is that the society will have more satisfied, contended, tolerant and empathetic individuals; they will be more productive in their social operations. This essentially yields a more sustainable social development. There will be more synergy and less competition among individuals and groups as the focus is to make individuals fully functioning to their full potential in unique ways. There will be fewer crimes in our societies as individuals are more satisfied and contended. Any tendency of any individual toward committing a crime can be proactively diagnosed within the mainstream education system that focuses on psychological and neurological characteristics of individuals. As a result, we will have more peaceful societies on the whole. There will be fewer individuals with negative psychological disorders (Webb, 2008; Silverman, 2004)) or conditions, firstly as the individuals are more satisfied and contended, secondly because we embrace diversity, more specifically neurodiversity, and tend to accept individual differences more broadly and as something that enriches the society rather than restricting it. When the society gives and opportunity to every member of it to self-identify him or her and embark on path to reaching full potential through the mainstream education system, it results a just and fairer society. In a society with fewer man created problems, we have more time and resources to concentrate on real problems, or the unavoidable, such as finding treatment for cancer and better preparing for natural disasters. Individuals solving those problems are more productive, psychologically healthy (Maslow, 1968; 1993) and creative maximising the chances of finding better or ideal solutions. On the whole, there will be more predictability and consistency in our social operations and situations, with fewer unexpected events, or situations.

\section{CONCLUSION}

Authentic education allows individuals to develop better, or fully, meeting their individual requirements. A system of authentic education identifies individuals uniquely, rather than trying to fit everyone to a single and unjustifiably perceived hypothetical model. In such a system, individuals are accepted as they are, valuing their strengths, while allowing them to overcome any limitations, if any, gradually and in conducive environments. Aspirations of these individuals will be mapped in to more appropriate career paths, in a world of diverse opportunities. As a result, it has the promise of producing more empathetic, satisfied, creative and productive human beings. This is the starting point of a significant positive overall social change; the human resources are given the prominence ahead of mere economic aspects, contrary to widespread contemporary practices. It provides us with an opportunity to overcome some of the perennial problems such as high crime rates, high number of individuals with psychological and psychiatric problems and lack of productivity in operations and so on and so forth, of the contemporary society. In essence, an authentic educational framework provides an opportunity to have a sustainable social development.

\section{AUTHOR INFORMATION}

Dr. Chandana Watagodakumbura is currently a lecturer at the school of Electrical and Computer engineering of RMIT University, Melbourne, Australia. He has PhD and Master's degrees in Engineering obtained from the RMIT University and a Bachelor's degree in Engineering from the University of Peradeniya, Sri Lanka. He also has a Graduate Certificate in Higher Education obtained from the Monash University, Melbourne, Australia. Previously 
he has worked as an academic at the Monash University, University of Northern Virginia and University of Peradeniya. His current research interests are related to education in general and more specifically pursuing authentic education. E-mail: chandana.watagodakumbura@rmit.edu.au

\section{REFERENCES}

1. Armstrong, T. 2011. The Power of Neurodiversity: Unleashing the Advantages of Your Differently Wired Brain. Da Capo Lifelong Books.

2. Beale, R. and Jackson, T. 1990. Neural Computing - An Introduction. Institute of Physics Publishing.

3. Biggs, J. and Tang, C. 2011. Teaching for Quality Learning at University ( $4^{\text {th }}$ ed.). Berkshire: Society for Research into Higher Education and Open University Press.

4. Dabrowski, K. (with Kawczak A. and Piechowski M. M.). 1970. Mental Growth through Positive Disintegration. London: Gryf Publications

5. $\quad$ Dabrowski, K. 1972. Psychoneuroses Is Not An Illness. London: Gryf Publications

6. Dabrowski, K. 1977. Theory of Levels of Emotional Development (vol 1)-Multilevelness and Positive Disintegration. New York: Dabor Science Publications.

7. Entwistle, N. J. 1998. Approaches to Learning and Forms of Understanding. In Teaching and Learning in Higher Education, ed. B. Dart and G. Boulton-Lewis, 72-101. Melbourne, Australia: Australian Council for Educational Research

8. Kolb, D. 1983. Experiential Learning: Experience as the Source of Learning and Development, Prentice Hall.

9. Maslow, A. 1968. Toward a Psychology of Being. New York: Van Nostrand Reinhold.

10. Maslow, A. 1993. Farther Reaches of Human Nature. New York, N.Y., U.S.A.: Arkana.

11. Paul, R. and Elder, L. 2000. Critical Thinking - Tools for Taking Charge of Your Learning and Your Life. Pearson Education.

12. Ramsden, P. 2003. Learning to Teach in Higher Education ( $2^{\text {nd }}$ ed.). London: RoutledgeFalmer.

13. Silverman, L.K. 1998. Personality and Learning Styles of Gifted Children. In Excellence In Educating Gifted \& Talented Learners $\left(3^{\text {rd }}\right.$ ed), ed. Van Tassel - Baska, Denver, Colorado, USA: Love Publishing Company.

14. Silverman, L. K. 2002. Upside-Down Brilliance: The Visual-Spatial Learner, Denver: DeLeon Publishing.

15. Silverman, L. K. 2004. At- Risk Youth and the Creative Process. Paper presented at ARTernatives for AtRisk Youth Conference, May 14, Colorado Springs.

16. Watagodakumbura, C. 2012. Conceptualising Authentic Education. Paper to appear in Proceedings of International Journal of Arts and Science Conference, Dec. 2-7, Gottenheim, Germany.

17. Webb, J.T. (with Amend E. R., Webb N.E., Goerss J., Beljan P, and Olenchak F.R.) 2005. Misdiagnosis and Dual Diagnoses of Gifted Children and Adults: ADHD, Bipolar, Ocd, Asperger's, Depression, and Other Disorders. Great Potential Press

18. Webb, J. T. 2008. Dabrowski's Theory and Existential Depression in Gifted Children and Adults. Paper presented at the Eighth International Congress of the Institute for Positive Disintegration in Human Development, August 7-9, Alberta, Canada.

19. Zull, J. E. 2002. The Art of Changing the Brain: Enriching the Practice of Teaching by Exploring the Biology of Learning. Stylus Publishing. 